\title{
Seismogenic faults along the major suture of the plate boundary deduced by dislocation modeling of coseismic displacements of the 1951 M7.3 Hualien-Taitung earthquake sequence in eastern Taiwan
}

\author{
Ling-Ho Chung a, Yue-Gau Chen ${ }^{\mathrm{a}, *}$, Yih-Min Wu ${ }^{\mathrm{a}}$, J. Bruce H. Shyu ${ }^{\mathrm{a}, \mathrm{b}}$, Yu-Ting Kuo ${ }^{\mathrm{a}}$, Yu-Nong Nina Lin ${ }^{\mathrm{a}}$ \\ a Department of Geosciences, National Taiwan University, Taipei 106, Taiwan, ROC \\ b Tectonics Observatory, Division of Geological and Planetary Sciences, California Institute of Technology, Pasadena, CA 91125, USA
}

\section{A R T I C L E I N F O}

\section{Article history:}

Received 5 July 2007

Received in revised form 13 February 2008

Accepted 21 February 2008

Available online 7 March 2008

Editor: R.D. van der Hilst

\section{Keywords:}

Coseismic displacement

Plate boundary

Active fault

Dislocation model

Taiwan

\begin{abstract}
A B S T R A C T
Research at plate boundaries generally focuses on the kinematics of plate motions, the genesis of large earthquake, and natural resources. However, often the present state of knowledge is still insufficient to reveal the details of such dynamic systems. To define in more detail the dynamics of, a major plate boundary fault the Coastal Range Fault, eastern Taiwan, we use seismologic and geodetic data to unravel its subsurface geometry and relevant fault behavior. By recomputing the archive triangulation datasets (1917-1978), and using a dislocation algorithm, we determine that it consists of three segments. Our model results are consistent with the observation of the 1951 M7.3 Hualien-Taitung earthquake sequence: that the southern two segments are both oblique-slip faults with significant thrust components, while the northern segment is a pure strike-slip fault. According to our model each segment has the potential to produce an earthquake larger than M7. However, based on GPS observations and seismic records, slip on the southern segment may take the form of aseismic creep and multiple moderate earthquakes, rather than large events with long recurrence interval as occur on the two more northerly segments. With regard to the central segment, the epicenter distribution of catalogued earthquakes occurring after 1951 reveals the presence of a seismic gap, indicating that slip on this segment is predominantly coseismic, with a correspondingly higher potential for large earthquakes in the future.
\end{abstract}

(c) 2008 Elsevier B.V. All rights reserved.

\section{Introduction}

Located at a well-known plate boundary between the Philippine Sea and Eurasia plates, where arc-continent collision began in the late Miocene, the island of Taiwan is tectonically and seismically active (Suppe, 1984; Tsai, 1986; Ho, 1986; Teng, 1990). Since active plate boundary are the most dynamic tectonic setting on the earth, research on the kinematics of plate motions, the genesis of large earthquake, and mineral resources has long been focused on these regions. However, scientists are still working the details due to sparse observation networks in many places. Taiwan, where dense geodetic and seismic networks have both been established for several decades, may be one of the best plate boundaries for a detailed study of fault dynamics. This study takes advantage of previous studies of the major plate boundary fault, the Coastal Range Fault (CRF) system in eastern Taiwan.

Given the island's dense population, land-use planning and seismic hazard mitigation require the identification of the major seismogenic

\footnotetext{
* Corresponding author. No. 1, Sec. 4th, Roosevelt Road, Department of Geosciences, National Taiwan University, Taipei 106, Taiwan, ROC. Tel.: +886 2 23697648; fax: +8862 23644625.

E-mail address: ygchen@ntu.edu.tw (Y.-G. Chen).
}

sources. Based on GPS geodesy, there is currently $7 \mathrm{~cm} / \mathrm{yr}$ shortening between the offshore islands in the east and the Taiwan Strait in the west. In the southern Longitudinal Valley (LV), about one third of this shortening occurs within LV, (Fig. 1) (Yu et al., 1997; Yu and Kuo, 2001) and takes place right across the major fault, the CRF, by aseismic creep. The CRF is the most important active fault within the LV, as has been pointed out by other independent studies of the geomorphology and seismology (Shyu et al., 2005a; Wu et al., 2006a). Previous modeling studies of interseismic deformation across Taiwan presented a 2D interpretation across the LV (Hsu et al., 2003; Johnson et al., 2005), but did not address the along-strike variations that will be considered in this paper. In order to understand the kinematics and major seismic sources along this extraordinarily active fault system, the present study lays out a fault model describing the CRF, including its dimensions and segmentation.

As has been done in other studies, the geodetically measured surface displacements can be used to derive the geometry of the seismogenic fault [e.g., Fluck et al., 1997; Larson et al., 1999; Klotz et al., 2001; Wang et al., 2003]. The 2003 Chengkung earthquake permitted a detailed description of the southern segment of CRF (Wu et al., 2006a). We have the opportunity to carry out a similar analysis of the fault's other segments. To achieve this, we need the coseismic ground slips for the more northerly portion of the CRF. There are available 


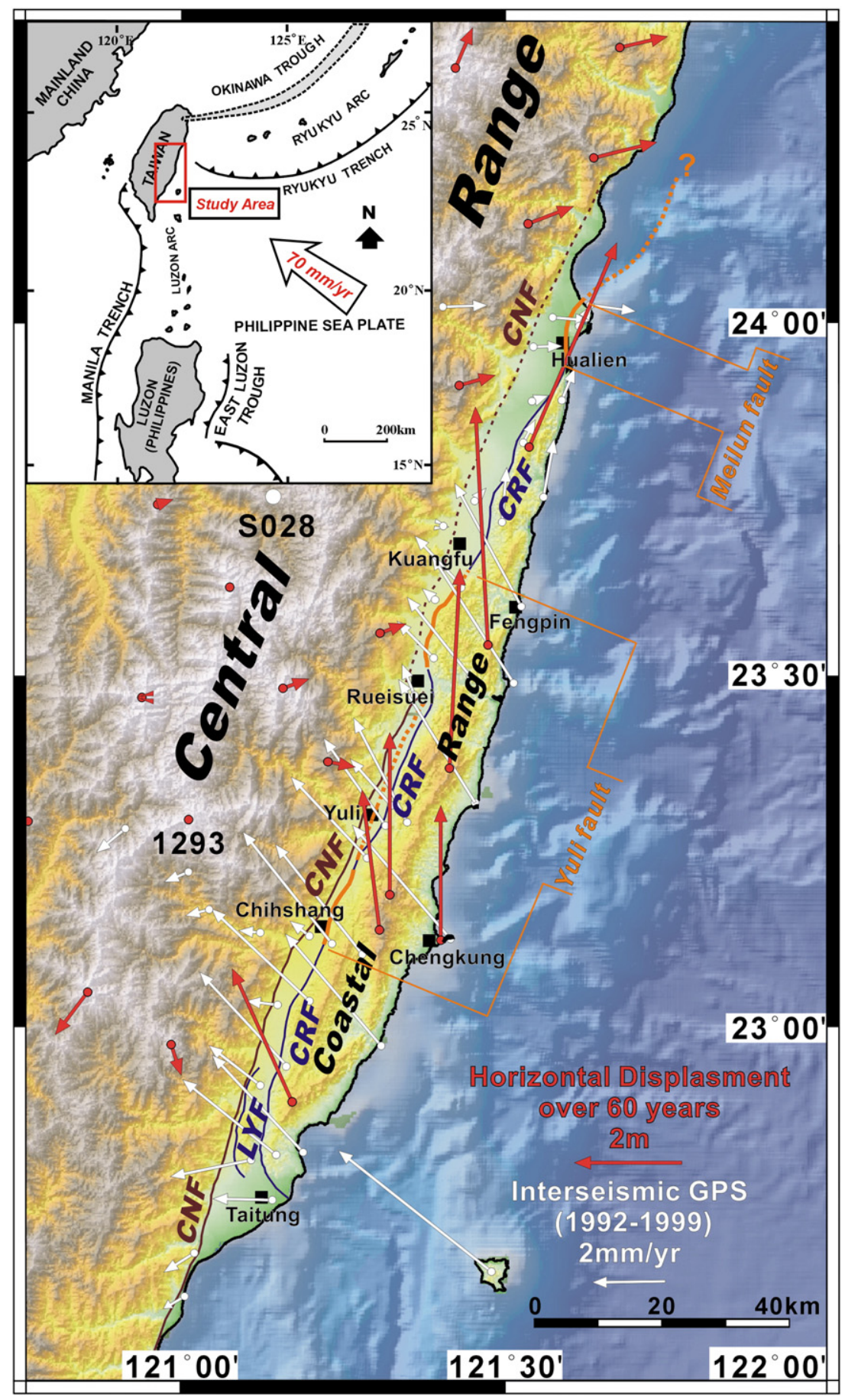

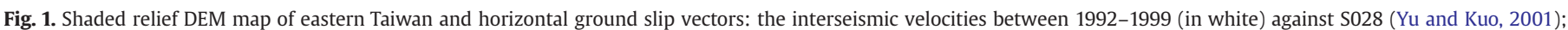

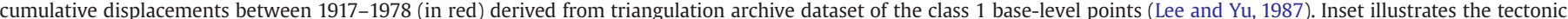

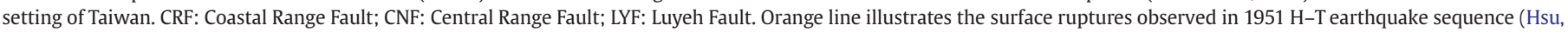
1962; Shyu et al., 2007).

triangulation datasets obtained in 1917/1921 and 1976/1978, corresponding to an interval of about $60 \mathrm{yr}$. If we could extract the coseismic component of the fault motion revealed by these datasets, we can perform such an analysis.

We were encouraged to believe that such an approach was feasible when we found that the regional displacement pattern of the southern LV, as calculated from the triangulation datasets, looks similar to the coseismic displacements of the 2003 Chengkung earthquake (Fig. 3a) (Chen et al., 2005; Wu et al., 2006a; Ching et al., 2007). This implies that the coseismic contribution is significant in the total motion on the CRF. By using the historical earthquake catalog for the timespan between the two surveys, we identified only one large earthquake event of significant magnitude in the LV, the 1951 Hualien-Taitung (abbreviated as $\mathrm{H}-\mathrm{T}$ hereafter) earthquake sequence. We therefore assumed this was the major contributor to the coseismic ground displacement recorded in the triangulation datasets. Based on this assumption, we subtracted an estimated value for the horizontal interseismic component using averaged rates derived from GPS records for the period 1992 to 1999 (Yu and Kuo, 2001). The resulting coseismic displacements, combined with an initial fault model suggested by field investigation, interseismic slips, and available focal solutions, permit us to construct a best-fit fault 


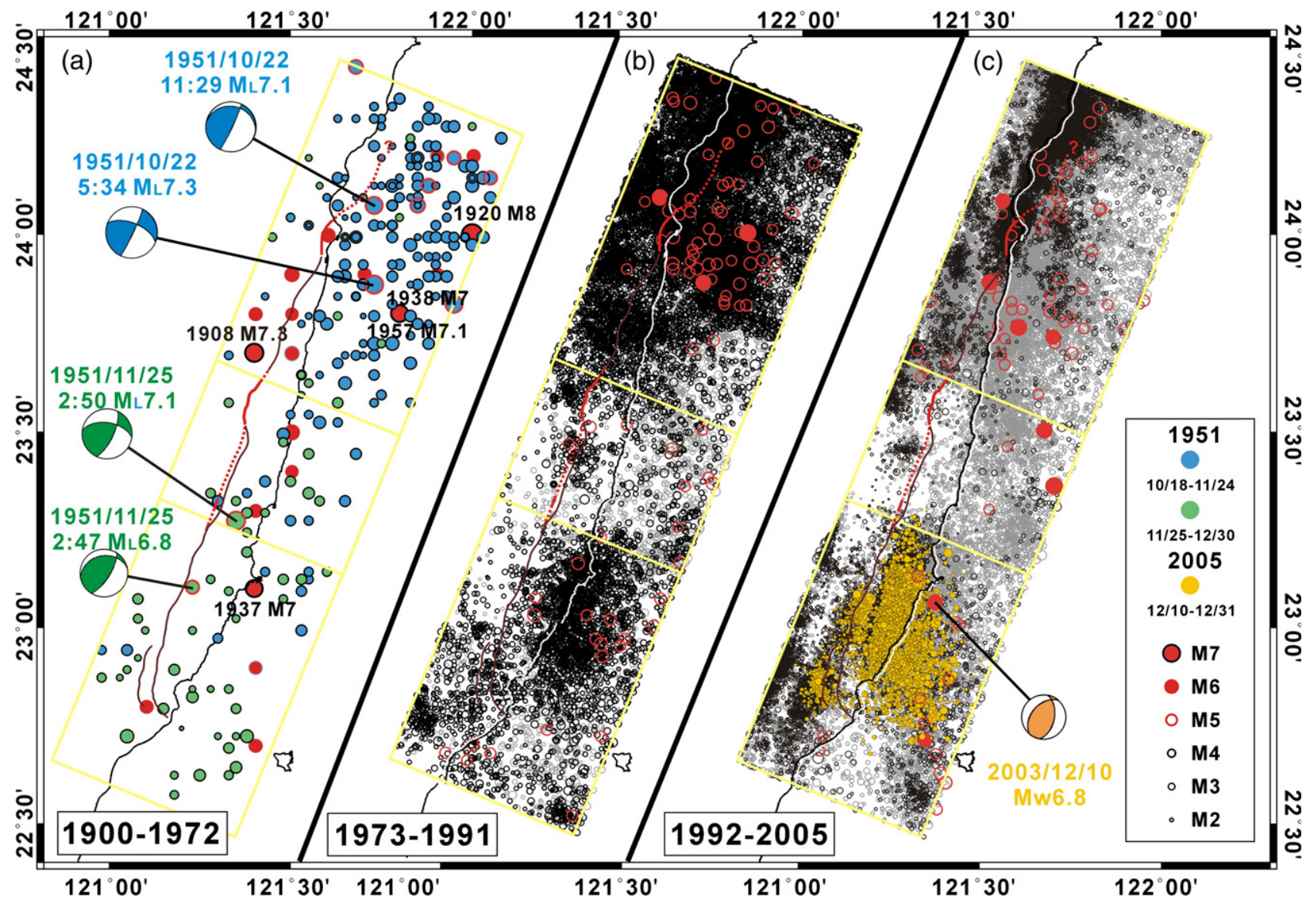

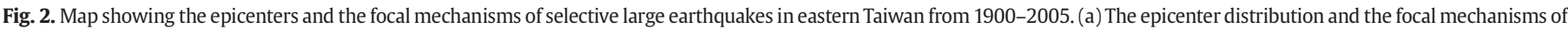

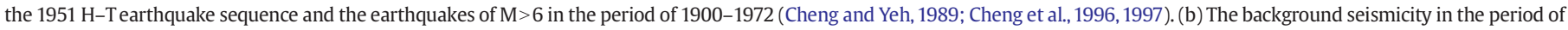

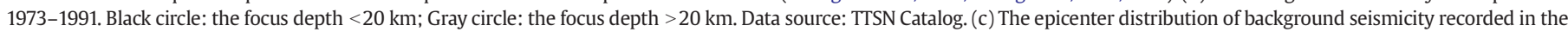
period of 1992-2005 and the focal mechanism of the 2003 Chengkung earthquake sequence (in yellow) Kuochen et al., 2007. Data source: CWBSN Catalog.

model using the method of dislocation simulation (Wu et al., 2006a; Okada, 1992).

\section{The Major Plate Boundary Fault: the Coastal Range Fault System}

\subsection{Tectonic background}

According to previous studies (Biq, 1965; Hsu, 1976; Shyu et al., 2005b; Wu et al., 2006a, b), the LV is one of the major geologic sutures within the collision zone of Taiwan. It separates two major tectonic entities - the Coastal Range and the Central Range to the east and west respectively. The Coastal Range is composed of materials mainly from the Philippine Sea Plate, such as igneous rocks from the Luzon volcanic arc and their associated turbidites, tectonic mélange, and fringing-reef limestones (Ho, 1986; Chen and Wang, 1986), representing a highly shortened arc association (Chang et al., 2001). The Central Range is composed of metamorphic rocks, predominantly schists and slates (Ho, 1986) from the Eurasian margin. The LV is the suture line between the Luzon Volcanic island arc and the metamorphic core of the continental sliver (Shyu et al., 2005b).

Structurally, the LV consists of two major fault systems: the eastdipping Coastal Range Fault (CRF) system and the west-dipping Central Range Fault (CNF) system, located at the eastern and western margins of LV respectively (Fig. 1). The CRF is characterized by high rates of oblique slip, at least along its southern segment, whereas mostly strike slip occurs along its northern segment (Shyu et al., 2005a). The CNF dips westward underneath the eastern flank of the Central Range (Fig. 1). Its existence is considered as part of the reason for the rapid uplift of the Central Range (Shyu et al., 2006b).

\subsection{The interseismic displacements in $\mathrm{LV}$}

The fast ground displacements across LV have long been known (Chen, 1974). Since 1981, a series of geodetic measurements focused on the CRF has been carried out to diagnose this active plate boundary (Yu and Lee, 1986; Yu and Liu, 1989; Liu and Yu, 1990; Yu et al., 1990, 1992). Based on the early 1980s trilateration networks and numerical modeling, from southern to northern LV the net horizontal motion across changes from $33 \mathrm{~mm} / \mathrm{yr}$ at an azimuth of $314^{\circ}$ to $25 \mathrm{~mm} / \mathrm{yr}$ of $0^{\circ}$ (Yu et al., 1990). To the north, the direction of the velocity vectors change systematically from approximately perpendicular to the strike of LV to approximately parallel to the strike. The largest strain rate $\left(8.4 \pm 0.5 \mu\right.$ strain/yr in $N 117^{\circ} \mathrm{E}$ ) was found in central $\mathrm{LV}$ (Yu and Lee, 1986; Yu et al., 1990). The GPS network was established in 1992. The measured velocities vary in both direction and amount along LV. In terms of the direction, the shortening to the north of the valley becomes ambiguous near Yuli and even somewhat extensional at Hualien (Fig. 1). In terms of the amount, the rate decreases from south to north showing the same trend as revealed by the previous trilateration surveys (Yu et al., 1997; Yu and Kuo, 2001). Compared with recent GPS observations (Yu et al., 1997; Yu and Kuo, 2001), the rates yielded by the trilateration surveys are 2 to 3 times faster found in northern segment of the CRF. It may be caused by the disturbance of 1986 earthquakes occurring near Hualien during trilateration survey (Yu et al., 1990). In addition, four short leveling routes were conducted during 1983-1988. The results shows fast rates of uplift $(18-20 \mathrm{~mm} /$ yr) between Chihshang and Yuli, but only half of this rate $(6-10 \mathrm{~mm} /$ yr) in Rueisuei (Yu and Liu, 1989). Furthermore, very fast continuous creep was reported for the southern segment of CRF, named the 
Table 1

The large events used in the this study and their focal parameters

\begin{tabular}{|c|c|c|c|c|c|c|c|c|c|}
\hline Date $(\mathrm{y} / \mathrm{m} / \mathrm{d})$ & GMT Time (h:m:s) & Latitude ${ }^{\circ} \mathrm{N}$ & Longitude ${ }^{\circ} \mathrm{E}$ & Depth (km) & Ms $\left(M_{L}\right)$ & Strike $\left({ }^{\circ}\right)$ & $\operatorname{Dip}\left({ }^{\circ}\right)$ & Rake $\left({ }^{\circ}\right)$ & Ref. \\
\hline 1908/01/11 & 03:35:00 & 23.7 & 121.4 & 10 & 7.3 & & & & 1. \\
\hline $1920 / 06 / 05$ & $04: 21: 28$ & 24.0 & 122.0 & 20 & 8 & & & & 1. \\
\hline $1937 / 12 / 08$ & 08:32:11 & 23.1 & 121.4 & 20 & 7 & & & & 1. \\
\hline 1938/09/07 & 04:03:18 & 23.8 & 121.8 & 0 & 7 & & & & 1. \\
\hline \multirow[t]{2}{*}{$1951 / 10 / 21$} & $21: 34: 14$ & 23.88 & 121.73 & 4 & 7.3 & 25 & 85 & 31 & 2. \\
\hline & & & & & & 292 & 59 & 174 & \\
\hline \multirow[t]{2}{*}{$1951 / 10 / 22$} & 03:29:31 & 24.08 & 121.73 & 1 & 7.1 & 25 & 85 & 73 & 2. \\
\hline & & & & & & 279 & 18 & 163 & \\
\hline \multirow[t]{2}{*}{$1951 / 10 / 22$} & $05: 42: 58$ & 23.83 & 121.95 & 16 & 7.1 & 45 & 75 & 60 & 2. \\
\hline & & & & & & 291 & 33 & 152 & \\
\hline \multirow[t]{2}{*}{$1951 / 11 / 24$} & $18: 47: 23$ & 23.10 & 121.23 & 16 & 6.8 & 32 & 70 & 70 & 2.3 . \\
\hline & & & & & & 259 & 28 & 133 & \\
\hline \multirow[t]{2}{*}{$1951 / 11 / 24$} & $18: 50: 30$ & 23.28 & 121.35 & 36 & 7.1 & 25 & 70 & 40 & 2.3 . \\
\hline & & & & & & 279 & 53 & 155 & \\
\hline $1957 / 02 / 23$ & $20: 26: 16$ & 23.8 & 121.8 & 30 & 7.1 & & & & 1. \\
\hline \multirow[t]{2}{*}{$2003 / 12 / 10$} & 04:38:15 & 23.10 & 121.34 & 10 & (6.6) & 36.5 & 50.2 & 94.2 & 4. \\
\hline & & & & & & 210.0 & 40.0 & 85.0 & \\
\hline
\end{tabular}

Ref: 1. (Cheng and Yeh, 1989); 2. (Cheng et al., 1997); 3. (Cheng et al., 1996); 4. (Kuochen et al., 2007).

Chihshang Fault (CSF), where the fault zone exposed in the outcrop with a width of several hundred of meters (Chu et al., 1994). Originally, the existence of the CSF was suggested by the existence of 3-6 m high terraces, and the total length was defined as $16 \mathrm{~km}$ near Chihshang area (Hsu, 1962). A variety of geodetic instruments, such as rod-type creepmeters, were thereafter installed to monitor the creep rate of the fault (Lee et al., 2000, 2001). After combining all data acquired between 1990 and 1997, creep on the CSF was calculated to be $22 \mathrm{~mm} /$ $\mathrm{yr}$ at an azimuth of $320^{\circ}$, including $16.5 \mathrm{~mm} / \mathrm{yr}$ shortening, $13 \mathrm{~mm} / \mathrm{yr}$ left-lateral motion, and $13 \mathrm{~mm} / \mathrm{yr}$ uplift (Angelier et al., 1997, 2000). The recent InSAR results are consistent with these field measurements, again providing constraint on the creep of southern segment of the CRF (Hsu and Bürgmann, 2006). In summary, the southern segment (i.e., CSF) of CRF is undergoing rather high rates of aseismic creep, with a predominance of dip slip. Going northward the shortening rate decreases, and strike slip becomes the predominant motion. In terms of the distinguishable pattern of the interseismic rates, the CRF can be segmented and the southern segment (i.e., CSF) is characterized by aseismic shortening.

\section{Background seismicity and fault segmentation}

Since the CRF is an active fault, background seismicity can be used to evaluate the fault's dimensions and geometry. For this task three different earthquake catalogs were used: the historic earthquake catalog from 1900-1972 (Fig. 2a) (Cheng and Yeh, 1989), the records from TTSN (Taiwan Telemetered Seismographic Network; 19731991), and the records from CWBSN (Central Weather Bureau Telemetered Seismic Network; 1992-2005). Our study area covers a rectangular area trending $\mathrm{N} 25^{\circ} \mathrm{E}$ with the width and length of 50 and $200 \mathrm{~km}$ respectively, as shown in Fig. 2. This region is based on the assumption that the CRF is dipping eastward with an angle larger than $45^{\circ}$ and extending downward to a depth of $30 \mathrm{~km}$. An extra $10 \mathrm{~km}$ have been added to each side due to possible uncertainty, especially for the old seismic record. In the timespan from 1900 to 1972 , only three events $\geqq M 7$ were recorded in the study area and its adjacent region. These include the 1908 (M7.3) and 1937 (M7) events and the main shocks of $1951 \mathrm{H}-\mathrm{T}$ earthquake sequence (Fig. 2a). All other large events occurred far offshore. Even if the offshore events were generated by the deeper part of the CRF, they would have made little contribution to the ground deformation (Table 1 ). There are other active fault systems located in the far offshore areas, especially the subduction-related systems in the northeast. Thus, based on the spatial relationship, we believe that most of these far-offshore events were generated by other systems. In the timespan from 1973 to 2005, no recorded earthquake was larger than magnitude 7 (Figs. 2b and c). After 1951 there seems to have been a period of seismic quiescence.

In addition, a clear seismic gap is distinguishable in the central LV, which has been mentioned in a previous seismological study (Kim et al., 2006) (Figs. 2b and c). On the basis of this seismic gap we would like to divide the CRF into three zones from north to south. In the northern zone, there are a number of M5 and M6 events, most of which are believed to relate to the northward subduction of the Philippine Sea plate. The resulting focal mechanisms are actually a mixture of normal, strike-slip, and thrust solutions (Kuochen et al., 2004). In the central zone, only a few earthquakes occurred at depths less than $\sim 20 \mathrm{~km}$, and none of them is $\mathrm{M}_{\mathrm{L} \geqq 5}$ (Figs. $2 \mathrm{~b}$ and $\mathrm{c}$ ). In the southern zone, the focal mechanisms are predominantly thrust. In addition, the spatial distribution of the epicenters coincides with the extent of the 1951 surface rupture (Figs. 2b and c). Based on this relationship, the CRF may be regarded as three segments, including the southern one suggested by interseismic behavior as described in the previous section.

To further measure the dip angle of each segment, the hypocenters within the northern and southern seismic zones were plotted. As was previously described by Kuochen et al. (2004), the hypocenters delineate an east-dipping listric geometry in the southern segment. It is interesting that the 2003 Chengkung earthquake sequence had the same distribution (Wu et al., 2006a; Kuochen et al., 2007) (Fig. 2c), which shows an eastward dip of $60^{\circ}$ near the surface but which decreases to $45^{\circ}$ below $18 \mathrm{~km}$ (Wu et al., 2006a). We use this proposed listric fault plane for the initial conditions of the southern segment of $\mathrm{CRF}$ in the later fault plane simulation. Unfortunately, the results for the northern segment have a scattered distribution and provide no information related to the fault geometry, probably because of the interference of other active fault systems. For the dipping angles of the central and northern segments, we only use information of the surface geology and the focal mechanisms of the near-fault earthquakes to give the initial conditions for the fault plane simulation (Kuochen et al., 2004).

\section{Large historical earthquake and geodetically measured surface displacements}

\section{1. $1951 \mathrm{H}$-T earthquake sequence and its surface ruptures}

This sequence began in the north near the city of Hualien with a $M_{L}$ 7.3 event at 21:34 on 21 October 1951 (GMT time), followed by two more large earthquakes in $8 \mathrm{~h}\left(\mathrm{M}_{\mathrm{L}} 7.1\right.$ at 3:29 and $\mathrm{M}_{\mathrm{L}} 7.1$ at 5:43). One month later ( 24 November), a $\mathrm{M}_{\mathrm{L}} 7.1$ earthquake struck the central LV (Twb, 1952). The entire sequence includes another 788 felt 


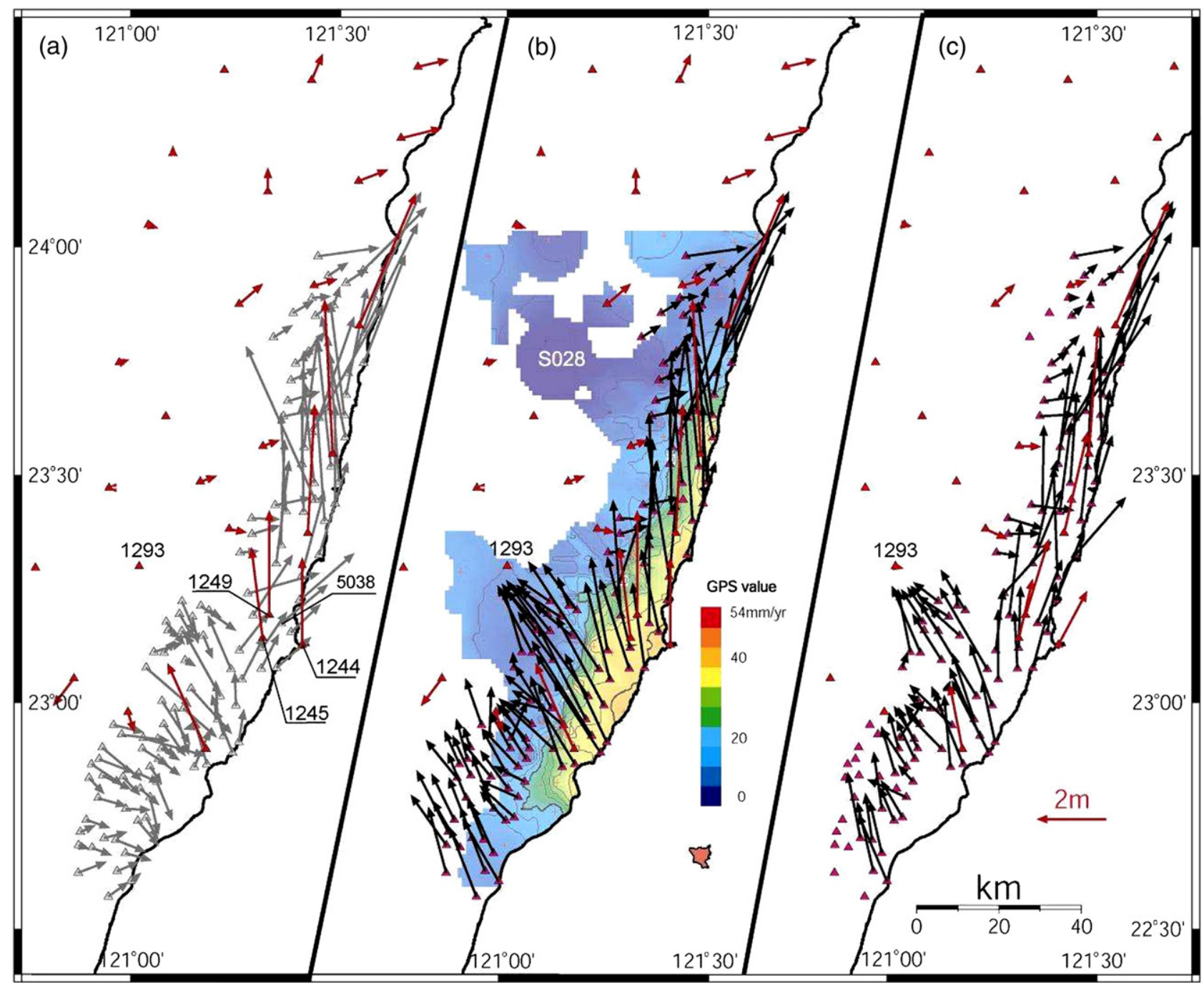

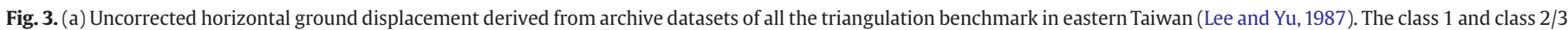

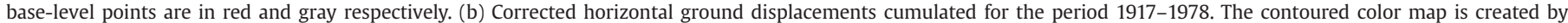

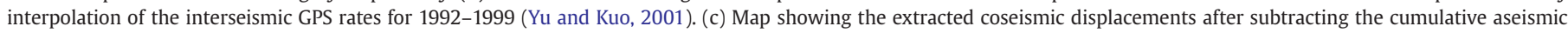
displacements (see Supplementary Material for details).

earthquakes. Cheng et al. (1997) relocated 280 events from this sequence by a Monte Carlo algorithm (Fig. 2a). It's interesting to learn that the aftershocks of the first $\mathrm{M}_{\mathrm{L}} 7.3$ event were mainly concentrated to the north of $23.6^{\circ} \mathrm{N}$, while the aftershocks of the second major main shock are distributed in the southern area (Fig. 2a). Four focal mechanisms are also computed from first motion studies in that report, indicating that the two main shocks are pure sinistral and oblique slip respectively (Fig. 2a and Table 1) (Cheng et al., 1996, 1997).

Associated with two main shocks, two surface ruptures were observed. They are named the Meilun Fault and the Yuli Fault in the north and south respectively (Fig. 1). Both of them were regarded as sections of the CRF (Yang, 1953; Hsu, 1962). The Meilun Fault was observed to run ca. $7 \mathrm{~km}$ near the urban area of Hualien and then to continue northward into the sea. Its vertical and horizontal offsets across the rupture were observed as ca. $1.2 \mathrm{~m}$ and $2 \mathrm{~m}$ with left-lateral sense (Hsu, 1962; Shyu et al., 2005a), which is actually inconsistent with the published focal solution of pure strike slip (Cheng et al., 1997). We will discuss this discrepancy later in the discussion. The Yuli Fault was found to run ca. $42 \mathrm{~km}$ from Kuangfu to Chihshang. The eastern side of the ruptures were raised up by about $1 \mathrm{~m}$ to the north of Rueisuei, but became smaller and ambiguous to the south. Based on photographs taken in the post-earthquake investigation, the fault scarp shows the strike and dip slips are $163 \mathrm{~cm}$ and $130 \mathrm{~cm}$ respectively (Hsu, 1962; Cheng et al., 1996; Shyu et al., 2005a, 2007). Based on reported 1 to $3 \mathrm{~m}$ ground slips produced during this earthquake sequence, we believe the coseismic displacement can be extracted from the ground displacements converted from the old triangulation dataset that spans the 1951 earthquake sequence.

\subsection{To extract the coseismic deformation from the old geodetic datasets}

Two triangulation surveys covering the entire island of Taiwan area were conducted in 1914-1921 and 1976-1979 (For eastern Taiwan the dates are 1917-1921 and 1976-1978). The ground displacements between the two surveys (converted from the class 1 base-level points) indicate rather rapid movement in eastern Taiwan (Chen, 1974; Biq, 1984). Different coordinate systems were used in two surveys, the first survey used Hayford spheroid, and the second used Kaula spheroid. By using Cunnigham's azimuth formula to correct the uncertainty based on the fixed point in the Central Range (Bomford, 1980), a later study reported 25 displacement of class 1 base-level points and other 115 points from class 2 and 3 (but latter two using another fixed point different from class 1) (Lee and Yu, 1987). The estimated average error of distance and azimuth are 6.12 PPM and $1.09 "$ respectively. In our study we recomputed 82 points from class $2 /$ 3 located in the study area against one of the class 1 points, No. 1293, 


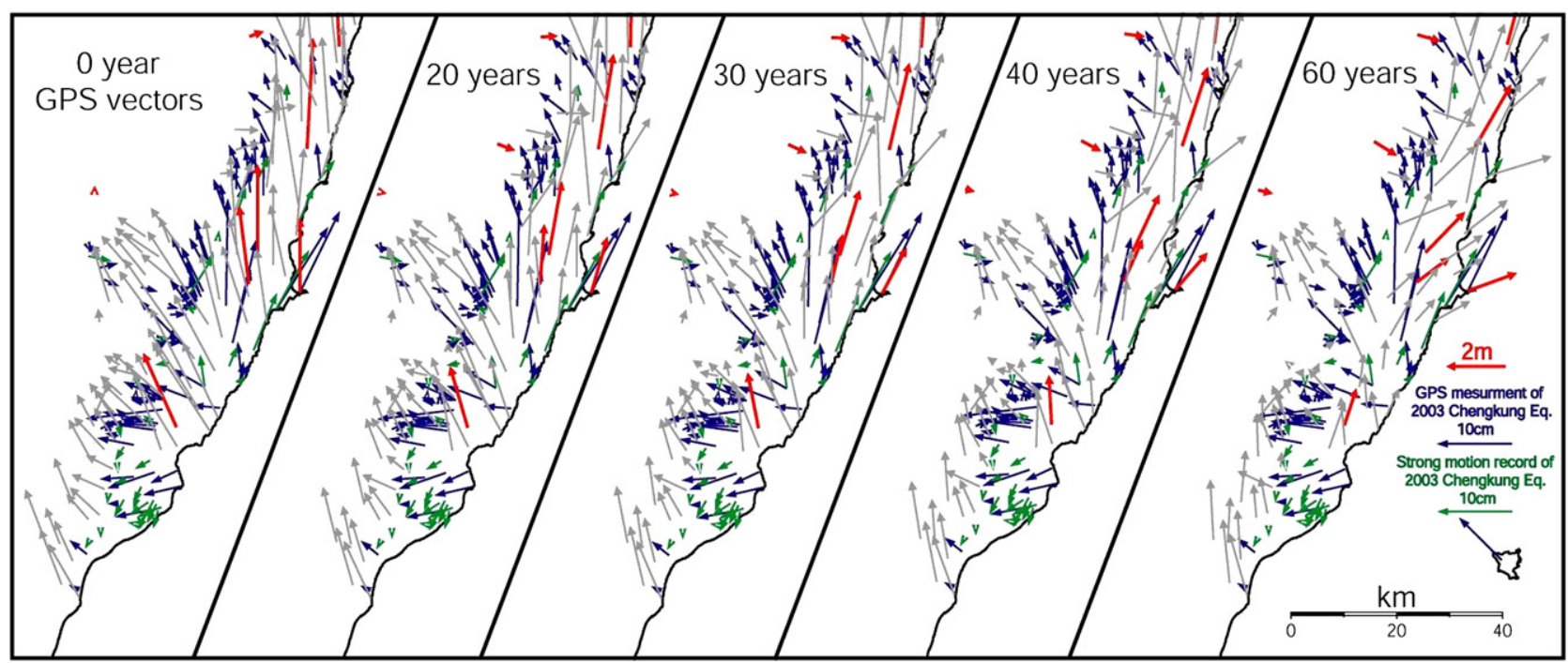

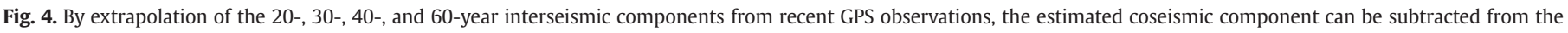

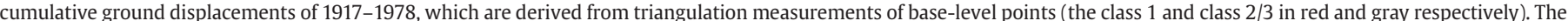

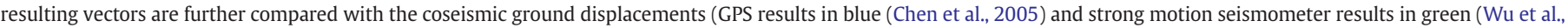
2006a)) recorded in the 2003 Chengkung earthquake. It is evident that the 30 -year result is the best fit.

which is located in the Central Range region (Fig. 3a). Unfortunately, in the area to the south of $23.30^{\circ} \mathrm{N}$ the derived vectors of class $2 / 3$ are inconsistent with those of class 1 . We therefore recalculated all the inconsistent class $2 / 3$ points using a correction value, which is derived from fitting the vector of the point 5038 with the average vector of three neighboring class 1 points (1244, 1245, and 1249) (Fig. 3b). After this, the discrepancy between class 1 and class $2 / 3$ disappear and two sets can be merged into one.

The total value of the vectors above has two contributors: the coseismic and 60-year interseismic components. Before going further we were unsure if we could successfully take out the coseismic component because fast creep is taking place in southern segment of the CRF as mentioned above. Fortunately, the characteristic radial pattern of the ground displacements revealed during the 2003 Chengkung earthquake can serve as a standard to distinguish the coseismic component (Mw 6.8, On Dec. 10) (Kuochen et al., 2007; Chen et al., 2005; Wu et al., 2006a; Ching et al., 2007; ) at least for the southern segment. Since the 60-year total surface displacements also show the radial pattern in the southern study area, we accordingly assume that the coseismic deformation produced by the 1951 earthquake sequence is significant in the displacement data recomputed in the previous paragraph. This finding encouraged us to extract the coseismic component by eliminating the 60-year interseismic displacement. However, there are only interseismic GPS reports for a few years available in eastern Taiwan (Yu et al., 1997; Yu and Kuo, 2001). Extrapolation seems the only way to proceed. Based on published literatures, we were surprised to found the value of 60 times the annual amount has been greater than the observed total displacement amount derived from triangulation datasets. It may be that the interseismic displacement varies from time to time. Although the simple extrapolation of the annual value of 1990s is incompatible, we further assume the directions and relative amounts of the velocities will be kept due to the same fault system. Based on this, we stepwise take out the interseismic component, using the annual vectors of the GPS result in 1992-1999 (Yu and Kuo, 2001) as the one-year increment. The resulting vectors for every ten-year increment are shown in Fig. 4. We quantitatively compare the directions of each resulting dataset with the 2003 Chengkung earthquake to obtain root mean square (RMS) values. By plotting the RMS vs. the years subtracted, we found $27.7 \mathrm{yr}$ will give the least RMS (Fig. 5). As a consequence, a total amount of $27.7 \mathrm{yr}$ of recent annual value was considered to be the total interseismic displacement. Finally, this amount was subtracted from the total horizontal surface displacements derived from the two triangulation surveys (Fig. 3c). The resulted coseismic displacements are distributed from 1.67 to $4.10 \mathrm{~m}$ and generally showing predominant sinistral slip in the time span along the LV between the two triangulation surveys.

We further partitioned the net horizontal displacement into components parallel and perpendicular to the CRF (Figs. 6a and b). Since there is no available interseismic vertical displacement, the

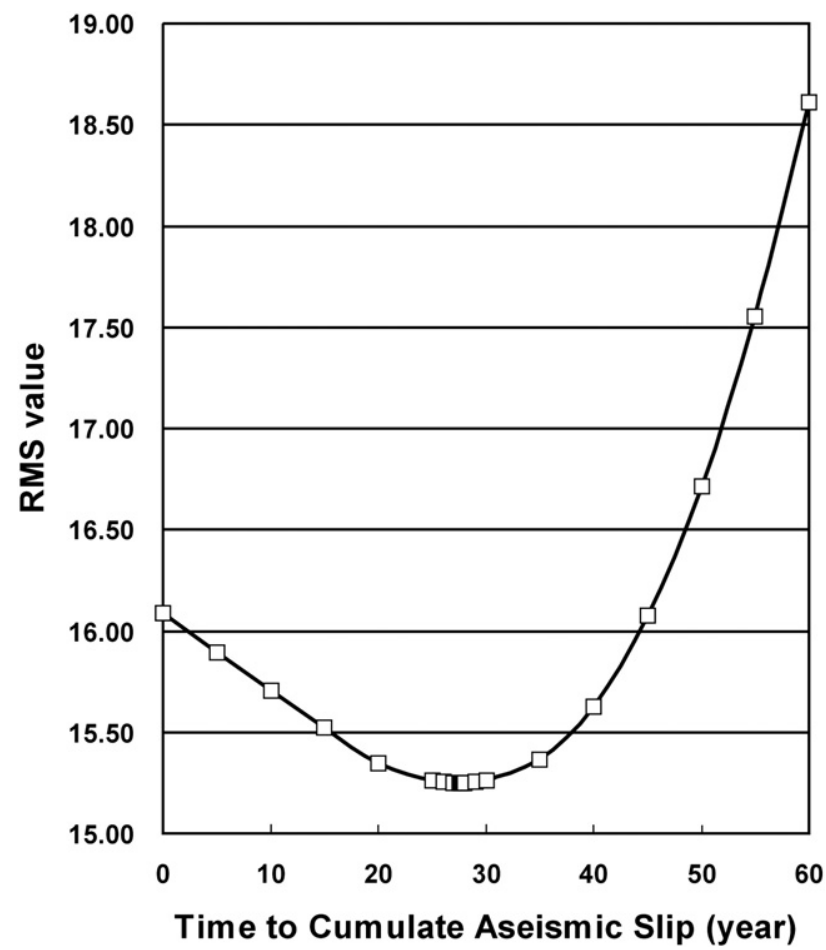

Fig. 5. The RMS values of the direction deviation between the major vectors of 2003 Chengkung earthquake and the cumulative horizontal displacements (1917-1978) after subtracting a supposed value given by years of recent GPS velocities. The minimum RMS yields a time value of $27.7 \mathrm{yr}$. 


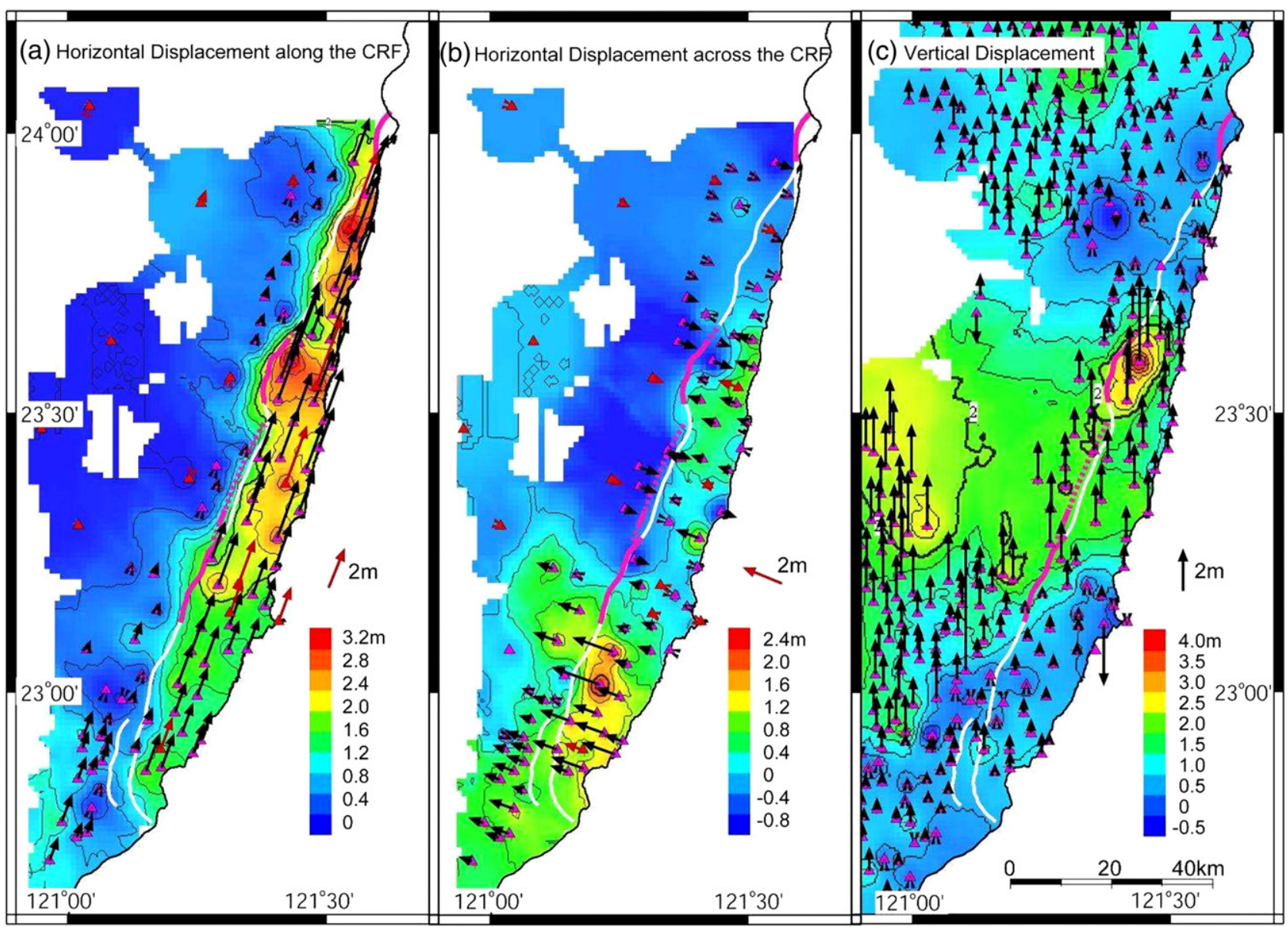

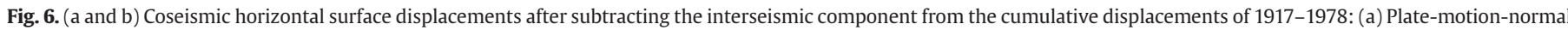

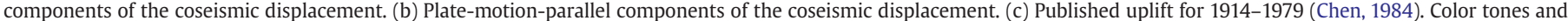

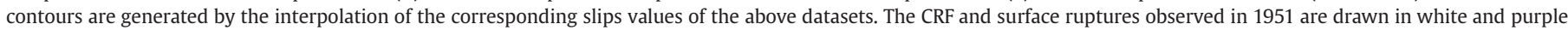
respectively. It is evident that the CRF can be divided into three segments from north to south on the basis of slip characteristics (see text for details).

previously published dataset of the total vertical displacements of 1914-1979 (Fig. 6c) (Chen, 1984) cannot be used in conjunction with our horizontal coseismic displacements. However, its pattern may be significantly influenced by the coseismic contribution as the horizontal pattern is. As revealed by Fig. 6, the horizontal and vertical components are generally concordant with each other. This pattern it again confirms that the CRF is composed of three distinct segments from north to south. Looking at the horizontal coseismic displacements, the northern segment is dominated by strike-slip component $(\sim 3 \mathrm{~m})$ with minor convergence. The central segment shows a strike slip similar to the scale of the northern segment, but with a larger thrust component $(\sim 0.8 \mathrm{~m})$. It is consistent with the field observation from the report of the 1951 surface rupture that significant vertical offsets were observed on the northern Yuli Fault (i.e., 1-2 m) (Hsu, 1962; Shyu et al., 2007), which is the only segment vertically offset up to a meter in the $1951 \mathrm{H}$-T earthquake sequence.

\section{Using dislocation simulation to construct a fault model}

With regard to the 2003 M6.8 Chengkung earthquake, the coseismic horizontal displacement has been well explained by a 3D fault model (Wu et al., 2006a), which locates the slip on the subsurface extension of the surface trace of the Chihshang fault (i.e., CSF and the southern segment of the CRF) (Lee et al., 2001). Surprisingly, we also found that the pattern of the coseismic horizontal displacement is similar to the recomputed coseismic displacements derived from the triangulation datasets (Lee and $\mathrm{Yu}, 1987$ ). Therefore, in an attempt to analyze the entire CRF we accordingly applied the same inversion method to the coseismic displacements recomputed above.

The applied initial fault plane strikes $\mathrm{N} 20^{\circ} \mathrm{E}$, parallel to the $\mathrm{LV}$. Initially we tried to model the fault as a single segment, but it would not satisfy the geodetic results. Since three segments are suggested by the constraints from background seismicity and recomputed triangulation dataset, we then tried a three-segment fault model. For the southern segment, we used the similar geometry of the 2003 Chengkung earthquake, except for fault length (Lee et al., 2003; Wu et al., 2006a; Ching et al., 2007; Kuochen et al., 2007). With regard to the central and northern segments, the spatial distribution of the seismicity provides no reliable information about fault geometry. Therefore, we used the data from field observations (Shyu et al., 2005a) and the previously published focal mechanisms (Kuochen et al., 2004) to constrain the initial fault geometry.

Table 2

Parameters of the best-fit fault model in this study

\begin{tabular}{|c|c|c|c|c|c|c|c|c|c|c|}
\hline \multicolumn{3}{|c|}{ West-south corner } & \multirow{2}{*}{$\begin{array}{l}\text { Strike } \\
\left({ }^{\circ}\right)\end{array}$} & \multirow{2}{*}{$\begin{array}{l}\text { Dip } \\
\left({ }^{\circ}\right)\end{array}$} & \multirow{2}{*}{$\begin{array}{l}\text { Length } \\
(\mathrm{km})\end{array}$} & \multirow{2}{*}{$\begin{array}{l}\text { Width } \\
(\mathrm{km})\end{array}$} & \multirow{2}{*}{$\begin{array}{l}\text { Strike } \\
\text { slip } \\
(\mathrm{cm})\end{array}$} & \multirow{2}{*}{$\begin{array}{l}\text { Dip } \\
\text { slip } \\
(\mathrm{cm})\end{array}$} & \multirow{2}{*}{$\begin{array}{l}\text { Total } \\
\text { slip } \\
(\mathrm{cm})\end{array}$} & \multirow[t]{2}{*}{ Mw } \\
\hline $\begin{array}{l}\text { Long. } \\
\left({ }^{\circ} \mathrm{E}\right)\end{array}$ & $\begin{array}{l}\text { Lat. } \\
\left({ }^{\circ} \mathrm{N}\right)\end{array}$ & $\begin{array}{l}\text { Depth } \\
(\mathrm{km})\end{array}$ & & & & & & & & \\
\hline 121.462 & 23.685 & 1 & 24 & 55 & & & 490.2 & 0.0 & 490.2 & 7.1 \\
\hline 121.307 & 23.270 & 1 & 16 & 55 & & & 494.0 & 552.0 & 740.8 & 7.4 \\
\hline 121.132 & 22.848 & 2 & 20 & 60 & & & 230.8 & 496.1 & 547.2 & 7.6 \\
\hline 121.216 & 22.820 & 18 & 20 & 45 & 45.00 & 25.00 & 320.6 & 170.1 & 363.0 & \\
\hline
\end{tabular}




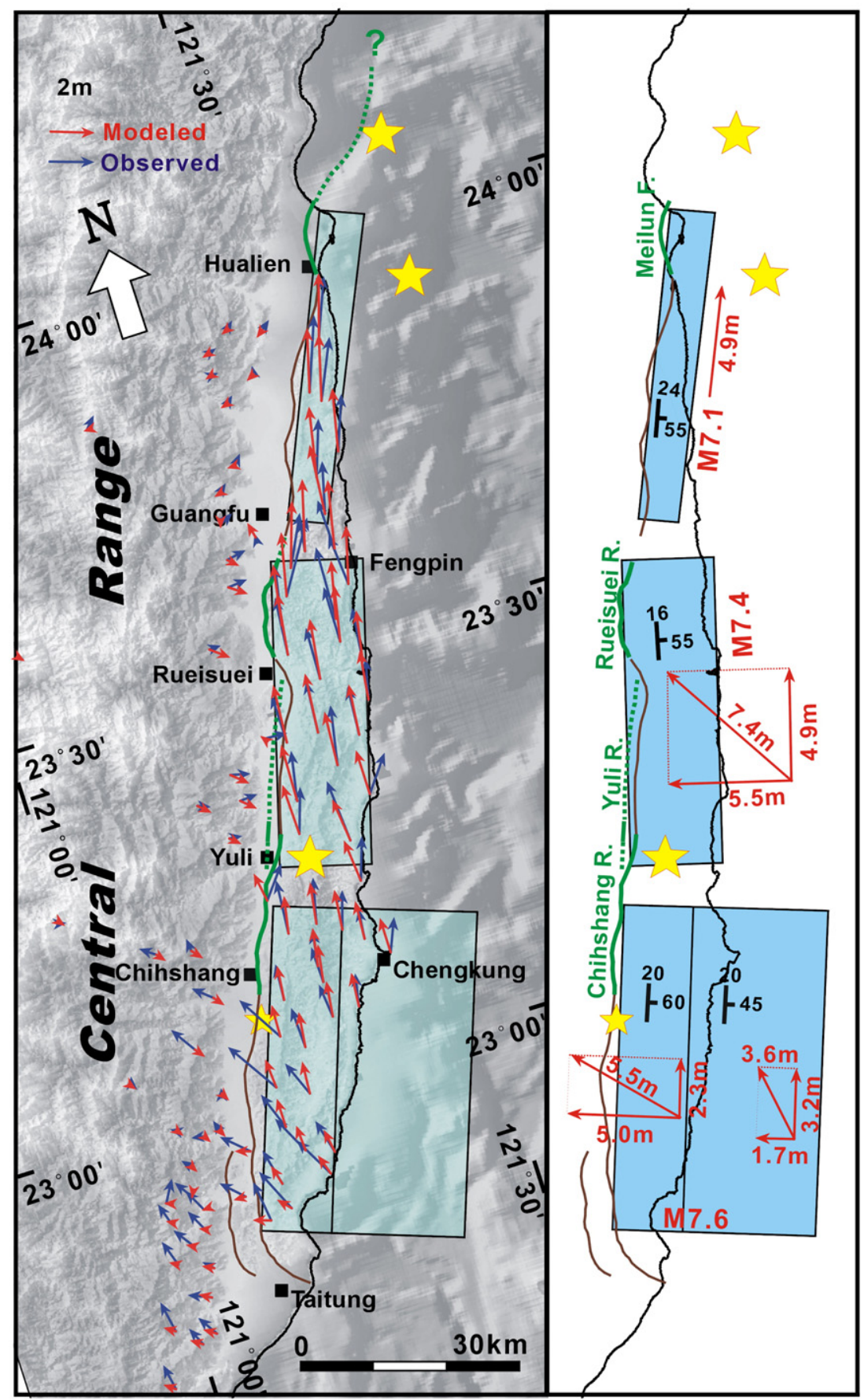

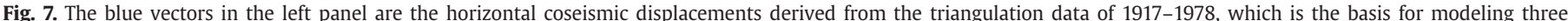

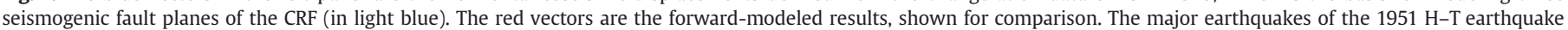

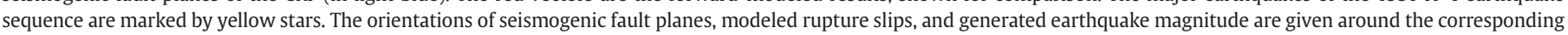
blue rectangles. The observed surface ruptures and published CRF are drawn in green and brown for reference.

\subsection{Dislocation fault model}

Our finite fault model is determined from inversion of the displacement field (Wu et al., 2006a), using the method for an elastic dislocation in a homogeneous half-space (Okada, 1992). The grid search is used to find the best-fit fault model via iteration of estimates of the amount and direction of all the horizontal coseismic surface displacements. The final three-segment CRF shows significantly different motion behaviors among segments. Fig. 6 displays all the coseismic displacements including those observed by the triangulation as well as the final forward-modeled results. The parameters of the best fit are listed in Table 2.
For the southern segment, the seismogenic fault consists of lower and upper fault planes (Fig. 6 and Table 2). Both of the fault planes extend $45 \mathrm{~km}$ along strike and cover depths of $18-36 \mathrm{~km}$ and 2-18 km respectively. The modeled slips on the upper and lower fault planes are $5.5 \mathrm{~m}$ and $3.6 \mathrm{~m}$ with rakes of $65.0^{\circ}$ and $27.9^{\circ}$ respectively. These slips are about 21 and 6 times the corresponding values for the upper and lower fault in 2003 Chengkung earthquake. Based on the area and the slip for each fault plane, the estimated magnitude is about Mw 7.6, and the energy is about 30 times that of the 2003 Chengkung earthquake. For the central segment, the best-fit fault plane strikes $\mathrm{N} 16^{\circ} \mathrm{E}$ and dips $55^{\circ} \mathrm{E}$ from a depth of $1 \mathrm{~km}$, with a width of $22.2 \mathrm{~km}$. The best-fit slip shows oblique sense, $4.94 \mathrm{~m}$ in left-lateral strike slip 
and a $5.52 \mathrm{~m}$ thrust component. The net slip is $7.41 \mathrm{~m}$, which can generate an earthquake of Mw 7.4. To the northern segment, the fault plane strikes $\mathrm{N} 24^{\circ} \mathrm{E}$ and dips $55^{\circ} \mathrm{E}$ from a depth of $1 \mathrm{~km}$, with a width of $10.0 \mathrm{~km}$. The sense of the slip is pure sinistral slip and the amount of slip is ca. $4.90 \mathrm{~m}$. The earthquake generated by this fault is estimated to have a magnitude of Mw 7.1.

\section{Discussion}

6.1. The comparison between fault model and surface ruptures of 1951 $H-T$ earthquake sequence

In spite of the initial assumption that the ground displacement determined from the triangulation occupations is dominated by coseismic contribution from the $1951 \mathrm{H}$-T earthquake sequence, the modeling results do not completely match what was observed in 1951. We will discuss the details segment by segment.

\subsubsection{October 22nd earthquake and its short surface rupture (Meilun} Fault)

The October 22nd earthquake produced $2 \mathrm{~m}$ and $1.2 \mathrm{~m}$ in horizontal and vertical separation along the surface rupture, the Meilun Fault, which is confined to the urban area of Hualien (Yang, 1953; Hsu, 1962; Bonilla, 1975). The total length of the surface rupture is only $8 \mathrm{~km}$. However, the northern fault plane in our model is as long as $42 \mathrm{~km}$ and slips about $5 \mathrm{~m}$ in pure strike-slip motion. There is no record of any other large earthquake event between the two triangulation occupations aside from the 1951 October 22nd earthquake. As suggested in the previous study (Shyu et al., 2005a), the surface rupture is only approximately $6 \%$ of the total length of the seismogenic fault. The rest of the fault plane was buried and might extend southward to Kuangfu, which is the northern end of another surface rupture that accompanied the subsequent November earthquake. The northern fault plane in our model is also buried at a depth of $1 \mathrm{~km}$ (Table 2), which is consistent with most of the field observations to the south of Hualien. The inconsistency regarding this northern end includes not only the extent of the surface fault but also the large vertical offset (ca. $1.2 \mathrm{~m}$ ). Other independent researchers working on the marine terraces also reported a high uplift rate of ca. $8 \mathrm{~m} / \mathrm{ka}$ (Lin, 1969; Yamaguchi and Ota, 2004) and pointed out the difference from other marine terraces distributed along the coast of the Coastal Range (Hsieh et al., 2004). We therefore propose that in Hualien the fault somewhat changes its geometry as it enters a transition zone to connect with other fault systems. Alternatively, other fault movements have been involved in the 1951 October 22nd earthquake, but we do not have enough ground displacement information to incorporate them into this study.

6.1.2. November 25th earthquake and observed three surface ruptures (Rueisuei, Yuli and Chihshang)

In a previous study (Shyu et al., 2007), the surface rupture of the November 25th earthquake was shown to be divided into three sections. From north to south they are Rueisuei, Yuli, and Chihshang (Fig. 7). The northern two exactly correspond to our modeled central segment. However, the southern one only covers one quarter of the modeled southern segment. All the displacements observed along the fault segment are less than $1 \mathrm{~m}$, except for the northern end of the central segment to the north of Rueisuei, where $1.6 \mathrm{~m}$ and $1.3 \mathrm{~m}$ displacements were photographed for the vertical and horizontal slips respectively (Hsu, 1962). As mentioned above, the southern segment experienced a Mw6.8 earthquake in 2003 (Wu et al., 2006a). This event produced coseismic surface displacements of more than $10 \mathrm{~cm}$ in the hanging wall $15 \mathrm{~km}$ away from the fault trace, but stood still along the near field of surface fault trace. The situation in November 1951 might have been similar. The earthquake rupture happened at depth and therefore did not generate a surface rupture corresponding to the entire length of the southern segment. This is consistent with our modeled result, in which slip on the southern segment terminates at a depth of $2 \mathrm{~km}$. However, for the southern segment we have another alternative explanation that will be discussed later in the next paragraph. For the central segments, the situation is somewhat more complicated. A single segment seems inconsistent with the field observations, which revealed two separated ruptures with different fault kinematics. The northern one, Rueisuei, is oblique slip, while the southern one, Yuli, is pure strike slip. Considering the multiple parallel fault traces that have been suggested exist between Rueisuei to Yuli (Shyu et al., 2007), we propose that slip was partitioned onto branch faults as it approached the surface. The strike-slip component from Rueisuei to Yuli was absorbed by another fault which did not reach the ground surface.

\subsubsection{A M6.8 foreshock of November 25th earthquake and another M7 earthquake in 1937}

The combined earthquake energy computed from modeled magnitudes of M7.4 and M7.6 for the central and southern segment respectively is much larger than expected from the single M7.1 main shock of Nov. 25th 1951. This may be partly explained by the contribution of a M6.8 foreshock that occurred 3 min ahead of the November main shock. Even so, we still need other contributions to satisfy the modeled result. The earthquake catalog includes a M7 earthquake that took place at Chengkung in 1937 (Fig. 2a) (Cheng and Yeh, 1989). This one, as well as the 2003 Mw6.8 Chengkung earthquake, reminds us that the southern segment may break in several moderate events instead of a single large one. Taking into account the significant creep rate (i.e., $2 \mathrm{~cm} / \mathrm{yr}$ ) along the southern segment (Yu and Liu, 1989; Angelier et al., 1997, 2000; Lee et al., 2003), a model involving several moderate contributors may be a better solution. Two other M5 events were reported north of the Chengkung earthquake in the southern segment (Lee et al., 2005). In this case, what we observed from triangulation datasets was a cumulative displacement and what we modeled is actually a synthesized fault slip. We may need more observations to confirm this unique fault behavior.

\subsection{Fault model and long-term uplift of the Coastal Range}

Our fault model implies that the CRF controls the motion of the Coastal Range. To confirm this, we further compared the geodetic data with the long-term uplift revealed by marine terraces that are distributed continuously along the eastern boundary of the Coastal Range (Fig. 7). The marine terraces studies (Liew et al., 1990, 1993; Yamaguchi and Ota, 2004; Hsieh et al., 2004) reported 1-2 levels and 6-9 levels of marine terraces to the north and south of Fengpin respectively; Fengpin is the boundary of the northern and central segments of our modeled CRF. Also, there is a clear transition zone located to the north of Chengkung that separates the marine terraces in the central and southern segments (Fig. 7) (Hsieh et al., 2004). Furthermore, the uplift rates of the marine terraces are also consistent with the modeled behavior. They are $<4,4-8$, and $6-11 \mathrm{~mm} / \mathrm{yr}$ for the northern, central, and southern segments respectively (Hsieh et al., 2004). For the northern segment, the low uplift rate strongly supports the pure strike-slip behavior of the CRF implied by our model. The higher uplift rates for the central and southern segment implies that tectonic convergence is causing more shortening in these segments.

\subsection{Earthquake quiescence of the central segment}

Looking at the spatial distribution of the epicenters from earthquake catalogs for the past $25 \mathrm{yr}$ (Fig. $2 \mathrm{~b}$ and c), numerous small earthquakes occurred in the northern and southern segments, but very few earthquakes occurred in the central segment. One previous study (Wang et al., 1994) attributed this phenomenon to high heat 
flow and geothermal activity, while another study (Kim et al., 2006) interpreted it as an interseismic period between two large earthquakes. Based on the dates of river terraces, the long-term uplift rate for the central segment is as high as $20 \mathrm{~mm} / \mathrm{yr}$ (Shyu et al., 2006a). This is almost equal to the rate of aseismic creep in the southern segment, but the current uplift rate is less than $10 \mathrm{~mm} / \mathrm{yr}$ according to a recent leveling survey in this area (Yu and Liu, 1989). It implies that the central segment may have a higher potential to release energy through large earthquakes than the southern segment. Since the central segment has constituted a seismic gap since the 1951 event, it is a likely seismogenic source for large earthquake in the future.

6.4. The effects of the interseismic component among three fault segments

To retrieve the coseismic component from old geodetic data, we assumed that 27.7-year annual vectors of the GPS measurement correspond to the total interseismic component (Yu and Kuo, 2001). This assumption is based on the seismological data from the 2003 Chengkung earthquake, which give a clear depiction of the fault geometry and associated ground movements for the southern segment of the CRF only. We actually have no constraints for the central and northern segments. We would like to evaluate the reliability of the interseismic component subtraction for these two segments. According to our model, if an earthquake of Mw7.1 occurs with a slip of $5 \mathrm{~m}$ in the northern segment, the activated fault length will be $42 \mathrm{~km}$, which covers nearly the entire northern Coastal Range. Also, our forward model demonstrates that the amounts of the ground displacements are very close to the amounts recorded in the original geodetic data, implying that the interseismic slip is relatively small in the northern segment. The situation for the central segment is similar. Examining our vector computation, the extracted interseismic components for the northern, central and southern segments are 8$14 \%, 15-25 \%$, and $24-50 \%$ respectively. We have the best constraint for the southern segment, in which the coseismic and interseismic components are comparable in size. In the central and northern segments, the interseismic component becomes much smaller. Our coseismic results in these two segments would not be seriously affected even if we did not subtract the interseismic component. This indicates that the reliability of our model is acceptable for the northern two segments, even though we did not have sufficient initial constraints.

\subsection{The mismatches between fault model and coseismic displacement in the southern segment}

Comparing the modeled and observed vectors (Fig. 7), the magnitudes fit rather well except for the area near to the surface fault trace along the southern segment. Also the observed vectors systematically show larger dip slip to the west. The CRF in the southern LV has two branches: the Luyeh fault and Lichi fault in the west and east respectively (York, 1976; Bonilla, 1977; Shyu et al., 2008). According to recent geodetic analyses, the Luyeh fault is dominated by a shortening of $\sim 12 \mathrm{~mm} / \mathrm{yr}$ (Yu et al., 1992; Lee et al., 1998). The discrepancy between the modeled and observed data may be caused by the contribution of the Luyeh fault, which we did not incorporate into the initial fault model due to insufficient constraints on either the fault geometry or the coseismic rupture behavior. It may be possible to improve our fault model when more detailed information on these factors becomes available.

\section{Conclusion}

By extracting the coseismic horizontal displacements from archived dataset of triangulation during 1917-1978, and modeling the data through a dislocation algorithm, a fault model is proposed for the CRF, one of the major active faults along the collisional plate boundary in eastern Taiwan. It consists of three seismogenic segments whose fault lengths (from south to north) are 45, 42, and $42 \mathrm{~km}$ respectively. The northern two fault segments dip $55^{\circ}$ to the east, but display a listric geometry, flattening to $45^{\circ}$, for the southernmost one. The corresponding earthquakes on these segments are modeled as Mw7.6, 7.4, and 7.1 respectively from south to north. The southern two segments are obliquely strike slip, while the northern segment is a pure strike-slip fault. This spatial variation in fault behavior is supported by the long-term uplift pattern revealed by study of marine terraces along the eastern coast of the Coastal Range. Since all three segments are buried according to the results of our modeling, there may be no surface rupture during earthquakes on these segments. In reality, during the $1951 \mathrm{H}-\mathrm{T}$ earthquake sequence $1.2 \mathrm{~m}$ vertical displacement was observed in Hualien, which is located at the northern end of our modeled northern segment. We therefore propose that the fault may change its geometry in the marginal transition zone, or that an unrecognized fault is involved, but there is no documented evidence to resolve this issue. Also, unlike the simple fault behavior of our model, the surface ruptures observed in the central segment in 1951 were complex: two separate faults with different structural styles were reported (Shyu et al., 2007). We suggest that the fault may branch into different surface strands that partition slip. Based on our model, rupture of the southern segment could generate an earthquake as large as Mw7.6. During the time covered by of the triangulation occupation, however, no earthquakes were reported except for the 1937 M7 event at Chengkung and the M6.8 foreshock of the 1951 November event. There may be other unrecognized/unrecorded earthquakes which contributed to the overestimation by our model. In addition, this segment has continuously released strain by aseismic creep over the past $15 \mathrm{yr}$. To fit our assumptions, the total ground displacement must include a 24$50 \%$ aseismic component. We therefore propose that the southern segment distributes strain into aseismic and smaller coseismic slips, a behavior which distinguishes it from its two more northerly counterparts. Finally, we would again emphasize the seismic gap presented by the central segment, a gap which is identified by the epicenter distribution of catalogued earthquakes after the $1951 \mathrm{H}-\mathrm{T}$ earthquake sequence. This implies that the central segment has a high potential to release energy through large earthquakes in the future.

\section{Acknowledgements}

We thank Drs. S.-B. Yu, C.-W. Lee, and H.-Y. Chen for the original geodetic data, and CWB for the earthquake catalog. The constructive comments from Drs. R.D. van der Hilst, R. Bürgmann, C. M. Rubin and P. Upton are highly appreciated. We are also grateful for valuable discussions with Drs. Y.-H. Lee, J.-C. Lee, W.-S. Chen, M.-L. Hsieh, J.-C. $\mathrm{Hu}, \mathrm{H}$.-T. Chu, and C.-P. Chang. This project is financially supported by CGS and NSC under grant numbers of 95-2119-M-002-041 and 962745-M-002-001-MY3.

\section{Appendix A. Supplementary data}

Supplementary data associated with this article can be found, in the online version, at doi:10.1016/j.epsl.2008.02.035.

\section{References}

Angelier, J., Chu, H.-T., Lee, J.-C., 1997. Shear concentration in a collision zone: kinematics of the Chihshang Fault as revealed by outcrop-scale quantification of active faulting, Longitudinal Valley, eastern Taiwan. Tectonophysics 274, 117-143.

Angelier, J., Chu, H.-T., Lee, J.-C., Hu, J.-C., 2000. Active faulting and earthquake hazard: the case study of continuous monitoring of the Chihshang Fault, Taiwan. J. Geodyn. 29, 151-185.

Biq, C.C., 1965. The east Taiwan Rift. Pet. Geol. Taiwan 4, 93-106.

Biq, C.C., 1984. Present-day manner of movement of the Coastal Range, eastern Taiwan, as reflected by triangulation changes. Geol. Soc. China Memoir 6, 35-40. 
Bomford, G., 1980. Geodesy, 4th ed. Oxford University Press, p. 120.

Bonilla, M.G., 1975. A review of recently active faults in Taiwan. Open File Report 75-41. U.S. Geological Survey, Menlo Park. 58 pp.

Bonilla, M.G., 1977. Summary of Quaternary faulting and elevation changes in Taiwan. Geol. Soc. China Memoir 2, 43-55.

Chang, C.P., Angelier, J., Huang, C.Y., Liu, C.-S., 2001. Structural evolution and significance of a mélange in a collision belt: the Lichi Mélange and the Taiwan arc-continent collision. Geol. Mag. 138, 633-651.

Chen, C.-Y., 1974. Verification of the north-northeastward movement of Coastal Range, eastern Taiwan, by re-triangulation. Bull. Geol. Surv. Taiwan 24, 119-123.

Chen, H., 1984. Crustal uplift and subsidence in Taiwan: an account based upon retriangulation results. Cent. Geol. Surv. Spec. Publ. 3, 127-140.

Chen, W.S., Wang, Y., 1986. Coastal Range geology in eastern Taiwan. Cent. Geol. Surv., Taipei. Taiwan Weather Bureau, Taipei.

Chen, H.Y., Yu, S.B., Kuo, L.C., Liu, C.C., 2005. Coseismic and postseismic displacement of the 10 December 2003 (Mw 6. 8) Chengkung earthquake, eastern Taiwan. Earth Planet Space 57, 1-17.

Cheng, S.-N., Yeh, Y.T., 1989. Catalog of the Earthquakes in Taiwan from 1604 to 1988. Institute of Earth Sciences, Academia Sinica, Taipei. 255 pp.

Cheng, S.-N., Yeh, Y.T., Yu, M.-S., 1996. The 1951 Taitung earthquake in Taiwan. J. Geol. Soc. China 39, 267-285.

Cheng, S.-N., Yu, T.-T., Yeh, Y.T., Chang, Z.-S., 1997. Relocation of the 1951 Hualien, Taitung earthquake sequence, conference on weather analysis and forecasting. Proceedings of Marine Meteorology and Seismology, in Commemoration of 100 Years of Weather Observation in the Taiwan Area, pp. 690-699.

Ching, K.-E., Rau, R.-J., Zeng, Y., 2007. Coseismic source model of the 2003 Mw 6.8 Chengkung earthquake, Taiwan, determined from GPS measurements. J. Geophys. Res. 112.

Chu, H.-T., Lee, J.-C., Angelier, J., 1994. Non-seismic rupture of the Tapo and the Chinyuan area on the southern segment of the Huatung Longitudinal Valley Fault, Eastern Taiwan. Annual Meeting of Geol. Soc. China, Taipei, pp. 1-5.

Fluck, P., Hyndman, R., Wang, K., 1997. Three-dimensional dislocation model for great earthquakes of the Cascadia subduction zone. J. Geophys. Res. 102, 20539-20550.

Ho, C.S., 1986. A synthesis of the geologic evolution of Taiwan. Tectonophysics 125, 1-16.

Hsieh, M.-L., Liew, P.-M., Hsu, M.-Y., 2004. Holocene tectonic uplift on the Hua-tung coast, eastern Taiwan. Quat. Int. 115-116, 47-70.

Hsu, T.L., 1962. Recent faulting in the Longitudinal Valley of eastern Taiwan. Memoir Geol. Soc. China 1, 95-102.

Hsu, T.L., 1976. The Lichi Melange in the Coastal Range framework. Bull. Geol. Surv. Taiwan 25, 87-95.

Hsu, L., Bürgmann, R., 2006. Surface creep along the Longitudinal Valley fault, Taiwan from InSAR measurements. Geophys. Res. Lett. 33.

Hsu, Y.-J., Simons, M., Yu, S.-B., Kuo, L.-C., Chen, H.-Y., 2003. A two-dimensional dislocation model for interseismic deformation of the Taiwan mountain belt. Earth Planet. Sci. Lett. 211, 287-294.

Johnson, K.M., Segall, P., Yu, S.-B., 2005. A viscoelastic earthquake cycle model for Taiwan. J. Geophys. Res. 110, B10404.

Kim, K.H., Chiu, J.M., Pujor, J., Chen, K.C., 2006. Polarity reversal of active plate boundary and elevated oceanic upper mantle beneath the collision suture in central eastern Taiwan. Bull. Seismol. Soc. Am 96, 796-806.

Klotz, J., Khazaradze, G., Angermann, D., Reigber, C., Perdomo, R., Cifuentes, O., 2001 Earthquake cycle dominates contemporary crustal deformation in Central and Southern Andes. Earth Planet. Sci. Lett. 193, 437-446.

Kuochen, H., Wu, Y.-M., Chang, C.-H., Hu, J.-C., Chen, W.-S., 2004. Relocation of the eastern Taiwan earthquakes and its tectonic implications. Terr., Atmos. Oceanic Sci. 15, 647-666.

Kuochen, H., Wu, Y.-M., Chen, Y.-G., Chen, R.-Y., 2007. 2003 Mw6.8 Chengkung earthquake and its related seismogenic structure. J. Asian Earth Sci. 31, 332-339.

Larson, K.M., Bürgmann, R., Bilham, R., Freymueller, J.T., 1999. Kinematics of the IndiaEurasia collision zone from GPS measurements. J. Geophys. Res. 104, 1077-1094.

Lee, C.-W., Yu, S.-B., 1987. Horizontal crustal movements in eastern Taiwan. The 6th Symposium on Science and Technology of Surveying and Mapping, pp. 127-134.

Lee, J.-C., Angelier, J., Chu, H.-T., Yu, S.-B., Hu, J.-C., 1998. Plate-boundary strain partitioning along the sinistral collision suture of the Philippine and Eurasian plates: analysis of geodetic data and geological observation in southeastern Taiwan. Tectonics 17, 859-871.

Lee, J.-C., Jeng, F.-S., Chu, H.-T., Angelier, J., Hu, J.-C., 2000. A rod-type creepmeter for measurement of displacement in active fault zone. Earth Planets Space 52, 321-328.

Lee, J.-C., Angelier, J., Chu, H.-T., Hu, J.-C., Jeng, F.-S., 2001. Continuous monitoring of an active fault in a plate suture zone: a creepmeter study of the Chihshang Fault, eastern Taiwan. Tectonophysics 333, 219-240.
Lee, J.-C., Angelier, J., Chu, H.-T., Hu, J.-C., Jeng, F.-S., Rau, R-.J., 2003. Active fault creep variations at Chihshang, Taiwan, revealed by creep meter monitoring, 1998-2001. J. Geophys. Res. 108, 2528.

Lee, J.-C., Angelier, J., Chu, H.-T., Hu, J.-C., Jengf, F.-S., 2005. Monitoring active fault creep as a tool in seismic hazard mitigation. Insights from creepmeter study at Chihshang Taiwan. C. R. Geosci. 337, 1200-1207.

Liew, P.-M., Hsieh, M.-L., Lai, C.-K., 1990. Tectonic significance of Holocene marine terraces in the Coastal Range. East. Taiwan Tectonophysics 183,121-127.

Liew, P.-M., Pirazzoli, P.A., Hsieh, M.-L., Arnold, M., Barusseau, J.P., Fontugne, M., Giresse P., 1993. Holocene tectonic uplift deduced from elevated shorelines, eastern Coastal Range of Taiwan. Tectonophysics 222, 55-68.

Lin, C.C., 1969. Holocene geology of Taiwan. Acta Geol. Taiwanica 13, 83-126.

Liu, C.-C., Yu, S.-B., 1990. Vertical crustal movements in eastern Taiwan and their tectonic implications. Tectonophysics 183, 111-119.

Okada, Y., 1992. Internal deformation due to shear and tensile faults in a half-space. Bull. Seismol. Soc. Am. 82, 1018-1040.

Shyu, J.B.H., Sieh, K., Chen, Y.-G., Liu, C.-S., 2005a. Neotectonic architecture of Taiwan and its implications for future large earthquakes. J. Geophys. Res. 110, B08402.

Shyu, J.B.H., Sieh, K., Chen, Y.-G., 2005b. Tandem suturing and disarticulation of the Taiwan orogen revealed by its neotectonic elements. Earth Planet. Sci. Lett. 233, 167-177.

Shyu, J.B.H., Sieh, K., Chen, Y.-G., Chung, L.-H., 2006a. Geomorphic analysis of the Central Range fault, the second major active structure of the Longitudinal Valley suture, eastern Taiwan. G.S.A. Bull. 118, 1447-1462.

Shyu, J.B.H., Sieh, K., Avouac, J.-P., Chen, W.-S., Chen, Y.-G., 2006b. Millennial slip rate of the Longitudinal Valley fault from river terraces: implications for convergence across the active suture of eastern Taiwan. J. Geophys. Res. B08403.

Shyu, J.B.H., Chung, L.-H., Chen, Y.-G., Lee, J.-C., Sieh, K., 2007. Re-evaluation of the surface ruptures of the November 1951 earthquake series in eastern Taiwan, and its neotectonic implications. J. Asian Earth Sci. 31, 317-331.

Shyu, J.B.H., Sieh, K., Chen, Y.-G., Chuang, R.Y., Wang, Y., Chung, L.-H., 2008 Geomorphology of the southernmost Longitudinal Valley fault: implications for evolution of the active suture of eastern Taiwan. Tectonics 27, TC1019.

Suppe, J., 1984. Kinematics of arc-continent collision, flippig of subduction, and back-arc spreading near Taiwan. Memoir Geol. Soc. China 6, 21-33.

Teng, L.S., 1990. Late Cenozoic arc-continent collision in Taiwan. Tectonophysics 183. 57-76.

Tsai, Y.B., 1986. Seismotectonics of Taiwan. Tectonophysics 125, 17-38.

TWB, 1952. The 1951 Earthquake Report. Taiwan Weather Bureau, Taipei. 83 pp.

Wang, J.-H., Chen, K.-C., Lee, T.-Q., 1994. Depth distribution of shallow earthquakes in Taiwan. J. Geol. Soc. China 37, 125-142.

Wang, K., Wells, R., Mazzotti, S., Hyndman, R.D., Sagiya, T., 2003. A revised dislocation model of interseismic deformation of the Cascadia subduction zone. J. Geophys. Res. 108, 2026.

Wu, Y.-M., Chen, Y.-G., Shih, T.-C., Kuochen, H., Hou, C.-S., Hu, J.-C., Chang, C.-H., Wu, C.-F., Teng, T.-L., 2006a. Coseismic vs. interseismic ground deformations, faults rupture inversion and segmentation revealed by 2003 Mw 6.8 Chengkung earthquake in eastern Taiwan. Geophys. Res. Lett. 33, L02312.

Wu, Y.-M., Chen, Y.-G., Chang, C.-H., Chung, L.-H., Teng, T.-L., Wu, F.T., Wu, C.-F., 2006b Seismogenic structure in a tectonic suture zone: with new constraints from 2006 Mw6.1 Taitung earthquake. Geophys. Res. Lett. 33, L22305.

Yamaguchi, M., Ota, Y., 2004. Tectonic interpretations of Holocene marine terraces, east coast of Coastal Range, Taiwan. Quat. Int. 115-116, 71-81.

Yang, Y.-C., 1953. Earthquakes in Hualien in the latest 41 years. Hualien Literatures 1 67-71.

York, J.E., 1976. Quaternary faulting in eastern Taiwan. Bull. Geol. Surv. Taiwan 25 $63-75$.

Yu, S.B., Kuo, L.C., 2001. Present-day crustal motion along the Longitudinal Valley Fault, eastern Taiwan. Tectonophysics 333, 199-217.

Yu, S.-B., Lee, C.-W., 1986. Geodetic measurement of horizontal crustal deformation in eastern Taiwan. Tectonophysics 125, 73-85.

Yu, S.-B., Liu, C.-C., 1989. Fault creep on the central segment of the Longitudinal Valley fault, eastern Taiwan. Proc. Geol. Soc. China 32, 209-231.

Yu, S.-B., Jackson, D.D., Yu, G.K., Liu, C.C., 1990. Dislocation model for crustal deformation in the Longitudinal Valley area, eastern Taiwan. Tectonophysics 183, 97-109.

Yu, S.-B., Yu, G.-K., Kou, L.-C., Lee, C.-W., 1992. Crustal deformation in the southern Longitudinal Valley area, eastern Taiwan. J. Geol. Soc. China 35, 219-230.

Yu, S.-B., Chen, H.-Y., Kuo, L.-C., 1997. Velocity field of GPS stations in the Taiwan area. Tectonophysics $274,41-59$ 